\title{
People with Dementia who go Missing: A Qualitative Study of Family Caregivers Decision to Report Incidents to the Police
}

\author{
Karen Shalev Green, Charlotte L. Clarke, Francis Pakes \& Lucy Holmes
}

'Abstract'

Walking and exercising are an important part of living well with dementia. People with dementia may have an inability to recognise familiar places, find a familiar location, or become disoriented and are more likely to become missing. The aim of this article is to identify what factors influence family caregivers of people with dementia reporting them missing to the police-. We used a qualitative approach based on semi-structured interviews of 12 family caregivers of people with dementia in England. We identify four factors that inhibit family caregivers from reporting a missing person incident to the police and three factors that prompt family caregivers to call the police. We discuss implications for improved policy and practices by law enforcement agencies, social services, health services and non-government organisations.

Keywords: dementia, family caregivers, missing persons

'Introduction'

This study examines the decisions of family caregivers of people with dementia as to whether or not report a missing person incident to the police. It is estimated that between 800,000 to 850,000 people are living with dementia in the UK (Alzheimer's Research UK, 2017; House of Commons Library, 2016). The National Police Improvement Agency (NPIA) (2011) indicates that-at least 40,000 people with dementia in England and Wales will go missing for the first time every year' (NPIA, 2011) and a minority of those go missing repeatedly. There is discrepancy as to the exact numbers. The National Crime Agency report that 20 percent of all missing adults in the UK are repeated cases. McShane et al. (1998) found that five percent (5 out of 106) of people with dementia went missing repeatedly. On the other hand, Bantry White \& Montgomery (2015) found that 27 percent of people with dementia (29 out of 106 individuals) in their sample from one UK police force went missing more than once.

People with dementia may have an inability to recognise familiar places, find a familiar location, or become disoriented and are unable to find the way back to where they travelled from or the location they were aiming to arrive at (Rowe \& Bennett, 2003; Hillier, Harvey, 
Conway, Hunt \& Hoffman, 2016). The American Alzheimer's Association (2011) found that six out of ten people with dementia wander (i.e venture into the community without supervision of a caregiver) and get lost in the community (Rowe \& Glover, 2001).

Consequently, Furumiya \& Hashimoto (2015) claim that all people with dementia who can walk as well as those who continue to drive are at elevated risk of getting lost or going missing. It is important to remember that wandering and going missing are inherently different in terms of frequency, timing and its nature (Rowe et al., 2015). Nonetheless, the American Alzheimer's Association (2011) argues that it is likely that the majority of people with dementia will have at least one missing incident during the course of their disease.

In the UK, a person is considered missing when their whereabouts cannot be established, until located, and their well-being or otherwise confirmed (College of Policing, 2016). Unlike practices in some countries, across the UK, there is no required time delay of 24 to 72 hours before reporting a person missing to the police. Edkins (2011) and Parr and Fyfe (2013) assert that 'missingness' is defined from the point of view of the reporting person. This means that a person may be missing when they themselves do not consider themselves to be missing at all. For example, where the person has changed their plans but did not communicate that to their relative.

In other circumstances, someone may not be missing but themselves experiencing feeling lost. For example, becoming separated from family or friends in a shop or a crowded street and not knowing where they are; or perhaps being unable to find their way home from routine outings, such as a daily walk. They may feel lost but will not be considered missing until they do not arrive at their expected location. 
According to a UK based study, the vast majority of people with dementia who are reported missing are found safe and well. Bantry White \& Montgomery (2014) found that 15 out of 281 (i.e. five percent) of people with dementia who were reported missing came to harm. This is a much higher figure than the national average of harm suffered by missing adults which stands on 2.9 percent (National Crime Agency, 2017).

When people with dementia go missing they are exposed to particular risks, such as dehydration, injuries such as bruising and abrasions, orthopaedic and soft tissue injuries, hypothermia, hyperthermia and death. The risks of harm while missing are associated with the age of the missing person, weather conditions, the terrain, time of day, length of time missing and the mode of transport used during the missing episode (Ali et al., 2016, Aud, 2004; Rowe, Feinglass \& Wiss, 2004).

Rowe \& Bennett (2003) emphasise the importance of an intensive search as people with dementia may succumb to death by exposure and drowning relatively quickly. Rowe et al., (2011) analysed 325 newspaper reports of people with dementia who went missing in the community. They found that 30 percent of their sample was found dead. The high percentage was not reflective of a typical ratio in the wider population and was a result of their sampling strategy. However, their findings suggest that those who died were found closer to the place last seen and took longer to find than those who were found alive. Of those found alive, 72 percent were found by the next day while only 40 percent of those dead were found by the next day. Of those not found by the next day 51 percent were found alive and 49 percent were found dead. For those not found until at least the fifth day after missing, only 20 percent were found alive. 
This sense of urgency is supported by iFIND which is an operational tool designed to improve the speed and effectiveness of searches for missing persons in the UK (Eales, 2016). Cases within the dataset include people with dementia that can still walk considerable distances even though they may be described as having mobility problems. It also informs officers that missing persons with dementia have been located lying in fields, ditches and bushes where they have fallen over and were not able to get back up. Officers are also asked to be aware there are incidents where the person living with dementia may have a desire to take their own life (p.56). It is therefore possible that any delay in a missing person being reported increases the length of time that the person is missing, thus putting them at greater risk (Bantry White \& Montgomery, 2015; UK Missing Persons Bureau, 2013).

Missing person incidents can have additional consequences, such as loss of independence. They may trigger institutional placements for the person with dementia. Many caregivers are relatives of the person with dementia (Department of Health, 2015), who are closely involved in maintaining their safety (Clarke et al. 2011; Mace \& Rabins, 2017) and the stress and anxiety associated with conjoining the carer role and family relationships (Draper, 2013; Zwaanswijk et al., 2013) can be exacerbated by a missing incident. This may lead to the institutionalisation of the person with dementia in a care home or within their own home, with caregivers locking people with dementia inside the house and restricting their movement outdoors (Askham, Briggs, Norman \& Redfern, 2007) and infantilising them (Marson \& Powell, 2014; Salari, 2006). Additionally, missing person incidents can also lead to an increased use of law enforcement and search resources (Rowe et al., 2015).

McShane et al. (1998) warned that police become aware of only a third of missing person cases involving people with dementia while approximately two thirds of these cases are never reported to the police. Bantry White and Montgomery (2015) found that only $0.5 \%$ of 
the regional dementia population estimates, in their study, was reported missing to police in 2008. Therefore, it is reasonable to assume that the majority of people with dementia who go missing are never reported to the police. This is an important issue to explore, because lack of reporting of such incidents can delay search activities and will lead to inaccurate official data (Bosick, Rennison, Gover \& Dodge, 2012; Tarling \& Morris, 2010).

Managing the possibility of a loved one going missing is part of the conflict caregivers face between the prevention of harm and the protection of a person's right to autonomy (Robinson et al., 2007), particularly since walking and exercising are an important part of living well with dementia (Bantry White \& Montgomery, 2015; Clarke, Keady, Wilkinson \& Gibb, 2011).

The extent to which the process of providing care to a family member with a dementing illness affects the physical and emotional well-being of the caregiver has received a great deal of attention in the literature. Common emotions experienced by caregivers include anxiety, rage, exhaustion, depression and guilt (Connell, Janevic, \& Gallant, 2001; Gonyea, Paris, \& de Saxe Zerden, 2008; Rosa et al., 2010; Sanders, Ott, Kelber \& Noonan, 2008). Therefore, caregivers have a heightened need for information that will assist and support them making decisions related to the freedoms and autonomy given to a family member with dementia'. Nevertheless, and despite the likelihood of people with dementia going missing, little is known about family caregivers' decision making process and willingness to approach the police and report their relative as a missing person.

Bearing in mind the risks people with dementia who go missing are exposed to, and how under-reported such incidents seems to be, a better understanding of prompting and inhibiting factors influencing family caregivers to report missing incidents may lead to 
reducing unnecessary delay in reporting practices. Thus, police officers will be able to initiate a search and find missing persons with dementia faster and return them safely.

'Methods'

\section{Study design}

The study utilised a qualitative method design, using semi-structured interviews.

\section{Participants}

The study is based on interviews with 15 family caregivers of a person with dementia. The characteristics of the caregivers and relationship to the person with dementia are presented in Table 1. We recruited participants who were related to the person with dementia. The person with dementia had to be living at home, either on their own or in their relative's home. Due to estimates of considerable under reporting of missing person incidents to the police, family caregivers were interviewed regardless of whether or not they reported a missing incident to the police. This was done to enable capturing the true experience of caregivers.

The wide inclusion strategy was also done in order to avoid the possibility that caregivers who may not regard an experience as a missing person incident would exclude themselves from the study by not making contact. The exclusion criteria were caregivers who were not related to the person with dementia or that the person with dementia was living in a care facility. Three caregivers who did not experience missing episodes were excluded from the analysis. Thus, the sample we discuss in this paper comprises 12 participants.

[Table 1 here] 
Participants were recruited via a snow-ball outreach strategy that finds an individual or a source that has the desired characteristics and uses the person or organisational social networks to recruit similar participants in a multistage process. After the initial source helps to recruit respondents, the respondents then recruit others themselves. This technique was chosen as it helped the authors gain access to this hard to reach population group. The use of this sensitive recruitment strategy is both appropriate and effective in enlisting the involvement of family caregivers of a vulnerable population (Sadler, Lee, Lim, \& Fullerton, 2010).

A purposive sample was used based on the characteristics of the population, e.g. living with dementia and are on the mailing list of at least one of the non-governmental organisations we approached, including The Alzheimer's Society, Missing People, Carers UK and Age UK. Information about the study and contact details of the principal researcher were circulated via an electronic flyer, and they distributed the information through their networks. Where relevant, participants were asked to share information about the study with other family caregivers who were part of their own social network. This was done in order to maximise the variance in the caregiver sample.

The authors acknowledge that these organisations are not engaged with by communities of ethnic minorities (e.g. BME) as much as they are by non-BME minority communities, with implications for recruitment for this study (All-Party Parliamentary Group on Dementia, 2013; Prior, 2013).

Participants lived across England (Hertfordshire, London, Merseyside, Norfolk, North Lancashire, Nottinghamshire, and Surrey). Family caregivers were caring for people living with different types of dementia, and with different levels of functioning, and of different age 
groups. Due to ethical restrictions explained below it is not possible to report on the demographic background in more detail.

Family caregivers who were interested in taking part in the study opted in and initiated contact with the first author via email or phone. The aims of the study were explained and a formal invitation letter, an information sheet and a consent form were sent to participants electronically. Once participants read the material and verbally agreed to take part in the study, an interview was carried out by one of two interviewers (first and fourth author).

\section{Data collection}

15 semi-structured interviews were conducted between August 2014 and December 2014. Interviews were conducted in a place of the participants' choice: 12 in caregivers' homes, two interviews by telephone and one interview in a café.

A topic guide was used to ensure that all the relevant topics were discussed. The content of the topic guide was based on discussions within the research team: (1) the context of being a carer to the person with dementia, (2) carers' understanding of the concept ofgoing missing, (3) missing prevention activities by carers, (4) response to a missing incident and (5) the impact of a missing incident on the carers and their family.

Caregivers were invited to describe any missing incidents they had experienced, and explain whether or not they reported them to the police and why. Where caregivers did not have previous experience of a missing incident, they were asked hypothetically whether they were likely to make such reports to the police and reasons in favour and against it. Caregivers were given a copy of the interview schedule if they wished to keep it, as well as a copy of the consent form with contact details of the interviewer. 


\section{Data analysis}

All interviews were audio recorded and anonymised. They were transcribed verbatim by an independent transcription company vetted by the University of XXX. Two authors (first and fourth authors) were involved in the entire process of data analysis. They read the transcripts individually and analysed the interviews they conducted. They verified each other's coding. Transcripts of the interviews were analysed using thematic analysis. Thematic analysis was considered to be the most appropriate method for this study as it is a qualitative approach that enables an in-depth understanding of the phenomenon. It offers a commitment to participants' viewpoints while conducting inquiries with minimum disruption to the natural context of the phenomenon. Thus, reporting of findings can be written in a literary style, rich in participant commentaries (Vaismoradi, Turunen \& Bondas, 2013). The coding process started with the broad topics of the interview followed by general themes for each topics followed by subthemes. The software programme NVivo version 10 was used to aid in the coding and analysis process. The final analysis was shared and discussed within the research team, which helped to enhance the quality of the analysis.

\section{Ethical considerations}

The study received ethical approval from the University of XXX Ethics Committee. Anonymity and confidentiality of caregivers were assured within the boundaries of professional responsibility on the part of the researchers to report any situation in which the safety of an individual was of concern. Any identifying details have been changed. Given that the people with dementia did not consent to take part in the study, the ethical committee prohibited the researchers from asking or reporting on the type of dementia people were living with, as that was considered to be a breach of their privacy. 


\section{'Findings'}

\section{Understanding of 'missing'}

At some point, the 12 caregivers were faced with the decision whether or not to call the police and report their relative as missing. Since this decision was based on their own assessment as to whether they considered their relative to be missing or not, we asked our caregivers how they defined the term 'missing'. All caregivers in this study defined 'missing' from their point of view rather than refer to an official definition by the police or other agencies and indicated that they considered the person with dementia missing when they did not know where they were.

Caregivers regarded two further factors as indicative of a person going missing. First, caregivers intuitively considered the person's vulnerability and assessed the potential risk or harm to the person with dementia. For example, are they able to find their way back or not, are they able to ask for help. For example,

'When you know their limitations, that then's a scary one. So I think limitations and your ability to do things makes a massive difference to whether it's a worry or not' (Brenda).

Second, caregivers considered the length of time that passed from the moment they last saw the person with dementia. These two factors varied between caregivers, and between missing incidents in cases where the person with dementia went missing more than once. For some, it was the moment they lost eye contact with them. For example,

'Out of sight for me was going missing'. (Claire) 
For others, it was a longer time period that followed an initial search. For

example,

'I know my mum goes out, and sometimes she doesn't answer the phone. She's not in a mood to speak. So I tend to just perhaps if you've got a more optimistic frame of mind, I tend to think she's okay and I will just keep persevering'. (Alison)

Alison points out that family caregivers may differ in their reaction to the same event and their assessment of potential risk to their relative, which would lead to a different reporting decision, saying that 'My sister would drive down there and ring the police...' In this instance Alison would not have made a report whereas her sister would do so.

\section{Missing person incidents}

Out of the 12 family caregivers nine had a repeated experience (two or more times) of the person with dementia going missing. One caregiver stated that his wife had been missing approximately twenty five times. Of the 12 caregivers, only seven reported incidents to the police, and two of these caregivers had made several reports. As in Table 2, 42 out of 52 missing incidents discussed by the participants were not reported to the police.

[Table 2 here]

Since there is no minimum time to wait until a missing person report can be made any time delay in reporting a missing person to the police is likely to be indicative of practical factors (e.g not carrying a mobile phone) or internal factors that influence that decision. Hence this issue was important to examine. Caregivers described missing instances that lasted from a few minutes to several hours or even a day. Missing incidents could occur while travelling a familiar route, such as a park or on the way to their local church or in more crowded environments such as local shops, restaurants, or a swimming pool while on a family holiday. For example, 
'I parked quite close to the bakery, and she went to get a loaf of bread and couldn't find her way back to the car'. (Stuart)

\section{Decision making process involved with reporting a missing person incident to the police}

Below is a summary of factors caregivers identified to influence their decision whether or not to report their relative as missing to the police. There were three key factors that prompted caregivers to call the police: (1) protection of the person with dementia; (2) an expectation that the police would be helpful by offering advice; and (3) an expectation that the police would be successful in locating their relative.

Protecting the person with dementia

The caregivers we interviewed emphasised consistently throughout the interviews the vulnerability of person with dementia and how worried and anxious they felt once they realised their relative was missing (for some this was an anticipatory anxiety as their relative had not become missing). It was clear to them that if they did not know where the person was, they were at risk and needed to be found as soon as possible. Thus, an overriding reason for reporting a missing incident to the police was to protect their relative from emotional or physical harm. For example,

'She potentially is starting to get stressed, because she doesn't know where she is'. (Mark)

See my problem was if she fell over and the big danger of course is if she falls over she could break her leg or hip or something of that nature, and she would just be lying there. (Elliot)

Expecting the police to be helpful by offering advice 
While some caregivers expressed a sense of helplessness at not being able to find the person and needing official assistance, two caregivers stated they called the police expecting to maintain responsibility for the search themselves. They were not sure how to proceed once they exhausted their initial search and made a call expecting to receive only advice and guidance and not that the police would 'take over' the search efforts. In those cases, caregivers called the 101 number (non-emergency number) rather than 999 (emergency number). For example,

I got to the point where I didn't know what to do, and so ringing them for advice. What do I do now? she's been gone for two and a half hours, what do I do now? (Mark)

The police response, in all cases described by the participants, was to escalate the search, sending officers to take a statement and caregivers were given an incident number.

Expecting the police to be successful.

Most caregivers called the police once they had exhausted their initial search and were unable to locate the person on their own. A missing person report not only offered them hope that their relative would be found, but also offered them some reassurance that more was being done to find them.

We thought that was the best thing to do, because we had tried on our own. Obviously I...the first thing I thought is that they can cover much more ground than what you can and they can organise things so that more ground is covered. (Elliot)

Several caregivers had multiple experiences of reporting an incident of being missing to the police. They explained that these previous experiences were positive and that officers were polite and supportive and found the missing person safely. Thus, they were inclined to make a 
new report because they trusted the police to be successful in locating the missing person safely again.

All caregivers in our sample instigated an initial search once they realised the person with dementia was missing. Fortunately, in most of the incidents related by caregivers, the missing person was found at an early stage and there was no need to report the incident to the police. This was sometimes achieved through the assistance of the public who came across the person with dementia and helped them back home or informed security staff or the police.

While a person was missing, most caregivers in our sample expressed some reluctance to report a missing incident to the police immediately. Of the 52 missing incidents participants experienced, they only made ten missing person reports (see Table 2). Despite the modest sample size, this finding offers an opportunity to consider that only a fifth of missing person incidents were reported to the police. This is consistent with McShane et al. (1998) who argue there is significant underreporting of such incidentsees. Furthermore, of these 52 incidents, 33 (17 percent) were experienced by just two of the participants, suggesting that for some people, being missing was a recurrent event, leading to being faced with this type of decision multiple times. This finding supports McShane et al., (1998) and Bantry White \& Montgomery’s (2015) assertion that a minority of people with dementia go missing repeatedly.

The findings uncover four inhibiting factors to contacting the police: (1) feelings of embarrassment and guilt; (2) fear of disapproval or judgement by police; (3) fear of negative reactions by person with dementia; and (4) a distrust of the police and desire to protect the relative.

Embarrassment and guilt 
One of the most common and important factors influencing a decision to not call and report the incident to the police or to delay calling, was caregivers' sense of guilt that their relative was potentially unprotected and unsafe, because they (in their mind) failed to keep them safe.

And then I felt irresponsible. It was a learning thing. It's like, well, you wouldn't take your eye off a baby. It's exactly the same thing. Probably worse because she's not going to grow out of it. She's going to get worse. (Kate)

'It was my mistake' (Paul)

Fear of disapproval or judgement by police

Given the sense of responsibility and guilt, experienced by caregivers, a few expressed fear that making a report to the police would lead to judgement of their ability to care for their relative.

'I think oh my god it's the police. And then I thought am I going to be in trouble...' (Julie)

Given that several of the caregivers expressed a sense of ownership and responsibility for the search for their relative with dementia, they were unclear as to whether they were expected, even 'allowed' to call the police. Thus, they feared they would be judged for wasting police time.

Actually, possibly expecting them to say, well, we know, she's an adult, she hasn't been gone long enough. I was quite pleased when they said somebody was going to come. (Mark)

Fear of negative reactions by person with dementia

For some caregivers, calling the police was very worrying, as they feared the person with dementia's reaction on finding out the police were called. This would have possibly led to the person with dementia being upset with them, increased tensions with other family members 
who may have reacted differently, and possibly loss of trust by the person with dementia. For example,

But, you know, if she was upstairs in a neighbour's, for instance, and suddenly she comes downstairs and there's sort of, you know, half the police force there, she wouldn't be happy...And my mum was very, very embarrassed about that and then feared that because, you know, the authorities knew about this incident that she would be sort of carted off. (Alison)

Distrust of the police and desire to protect their relative

Due to the deterioration of cognitive ability associated with dementia, some of the caregivers described their fear for their relative if they came in contact with the police or members of the public as well as a concern that their relative would become frightened or distressed. This was due to lack of confidence that police officers would know how to approach the person with dementia without distressing them. Thus, they preferred not to alert the police and to try to find the person they cared for by themselves. For example,

I'm just very anxious that because [her husband] can't communicate and he might find it quite scary... I think it would be nice to build a relationship with the police locally... and have a chat with them so that maybe we know who the people are. So if I said to somebody, here's a picture of my husband, this is him. So that at least they're aware and if they see somebody acting strangely they don't automatically jump on them, handcuff them and Taser them or whatever else they might do. (Brenda)

'Discussion'

The study examined factors influencing whether or not family caregivers of people with dementia will report missing person incidents to the police. This is an important issue to explore as it has received little attention to date. Our data suggests that only a fifth of missing incidents were brought to the attention of the police. This finding supports McShane et al.'s (1998) claim of considerable under-reporting of missing incidents of people with dementia to thepolice. 
The data also suggests that the majority of caregivers (9 out of 15) experience more than one such incident. This is a much higher percentage than McShane et al. (1998) and Bantry White \& Montgomery (2015) report. It may be a result of our small sample size, but it may also be due to the fact our sample included caregivers who did not report incidents to the police. We therefore propose that the 'true' rate of missing of people with dementia, whilst cared for by relatives, may be substantially higher than previously assumed. It is most important to realise that where there is a reluctance to report, sadly, lives may be put at risk unnecessarily.

Caregivers with experience or concern about being missing may have been more inclined to participate in this research, but none-the-less, these findings serve as a reminder of the vulnerability of people with dementia, and while most are found safe, as indicated by previous literature (Rowe \& Bennett, 2003; Rowe et al., 2011; Eales, 2016), several will come to harm or die as a direct consequence of being missing.

Managing a missing incident of a person with dementia is a type of difficult proxy decision caregivers must make on behalf of their relative with dementia. Thus, there is evident need for practitioners, such as GPs, law enforcement agencies and non-governmental agencies, to communicate openly with caregivers about the likelihood of a missing incident occurring as well as prevention strategies they may wish to consider in order to safeguard their relatives. For example, relieving boredom and continuing a habit or interest (Safeguarding Hub, 2017), using assistive technologies, or arranging for twenty four hour care at home, installing door alarms or activity monitors and recorders, etc (UK Missing Persons Bureau, 2013).

Our results suggest four factors inhibit family caregivers from calling the police when their relatives go missing (e.g. costs): embarrassment and guilt, fear of disapproval or 
judgement by police, fear of negative reaction by the person with dementia, distrust of police and the desire to protect their relative.

These four factors reflect caregivers overall desire to protect the person with dementia as well as themselves from any negative consequences of reporting missing incidents to the police. The findings also confirm the negative emotional effects caregivers can experience, as they discuss their fears and sense of guilt and responsibility. These are common emotions experienced by caregivers which can profoundly impact their own well-being (Connel et al., 2001; Gonyea et al., 2008; Rosa et al., 2010; Sanders et al., 2008).

Conversely, three factors prompt relatives to call the police when the person with dementia is found to be missing (e.g. incentives): the desire to protect the person with dementia, expecting the police to be helpful, and expecting the police to be successful in finding the missing person.

The caregiver's sense of responsibility for the safekeeping of the missing person was identified, in this study, as the dominant factor in their response to their relative going missing, as most participants in our study immediately initiated their own search and recruited family, friends and neighbours to assist them. It was only when they were unable to find the person that they considered calling the police. This ranged from minutes to several hours after the person went missing.

Furthermore, this study demonstrates that family caregivers intuitively understand the concept of 'missing' that is consistent with police and academic definitions in the sense that their relatives' whereabouts cannot be established, they have not been located and their welfare has not been confirmed (College of Policing, 2016; Rowe et al., 2015). However, caregivers' 
perception of the term is subjective and, as demonstrated in the study, the same incident can be judged differently by various family caregivers.

Furthermore, caregivers assessment of the situation depends on how their judgement of the likely risk of harm to person with dementia. This depends on the context of the situation as well as how vulnerable they deem their relative to be. Since dementia is a degenerative disease, people with dementia may lose abilities they previously had. Thus, a person who went missing at one point and was deemed relatively safe by their caregiver may now be considered highly vulnerable, leading the caregiver to report the incident to the police immediately.

The findings from this study may lead to policy and practice changes. The College of Policing's Authorised Professional Practice (APP) guidance and training should be updated to increase awareness about the issue amongst all officers but particularly response officers, neighbourhood policing teams, and missing person teams. This is to ensure a non- judgemental response when a person with dementia is reported missing and to ensure officers know how to work with family caregivers and how to approach people who are living with dementia and have been missing.

Neighbourhood policing teams should consider the issues discussed in this study when building relationships within the community in which they work. This could have two positive effects. First, it will increase caregivers' awareness about the risks of people living-with dementia going missing and the importance of reporting them missing to the police. Second, targeted events or communications could actually allow the police to 'get to know' people in the area who are at high risk of going missing and therefore could increase confidence and trust of the police by caregivers and the individual with dementia. This may not be practicable in some areas because of the expanse that neighbourhood teams cover but could be hugely valuable where possible. 
The police should undertake a public awareness campaign with the dual aims of encouraging people to report their loved one missing if they are concerned and reassuring the public that they know how to support people with dementia. This may be achieved as part of the Herbert Protocol scheme (Mayor's Office for Policing and Crime, 2018), where professional and family caregivers as well as friends can complete in advance, a form recording all vital details (such as medication required, mobile numbers, places previously located, a photograph etc.) in the event of a person with dementia going missing.

This study has a number of limitations which must be considered. The primary limitation is that the results are drawn from a modest sample of participants who experienced a missing person incident. Furthermore, the sample does not represent all ethnic groups living in the UK, who may be influenced by other factors. Finally, due to ethical restrictions it was not possible to learn more about the people with dementia and their background, such as age, type of dementia, etc.

\section{'Conclusions'}

The study proposes there is considerable underreporting of missing persons incidents to the police by family caregivers of people with dementia. The study also found a high percentage of repeated missing person incidents that were not reported to the police. The study helps us identify push and pull factors involved with the decision to report a missing person incident to the police.

In order to improve reporting practices and reduce delays in reporting missing person incidents, family caregivers of people with dementia should be recognised as requiring support and assistance as they are faced with the possibility of their relative going missing. Relevant 
agencies may benefit from proactive community work which reassures family caregivers of the advantages of reporting missing person incidents. For example, Health Care and/or Social Services professionals should discuss the possibility of a person with dementia going missing with caregivers, consider prevention strategies, as well as, discuss what caregivers should do, in case their relative goes missing.

Additionally, when a family caregiver reports a missing person incident, police officers and search and rescue volunteers should be reassuring and non-judgmental and should explain to the caregivers how a search is carried out and the process of investigation, as well as reassure them they will not be in trouble and that they are there to assist them. They should also be mindful caregivers may have important information about how best to approach and communicate with the missing person, considering their type of dementia and level of functioning.

\section{References}

Ali, N., Luther, S. L., Volicer, L., Algase, D., Beattie, E., Brown, L. M., Molinari, V., Moore, H., \& Joseph, I. (2016). Risk assessment of wandering behavior in mild dementia. International Journal of Geriatric Psychiatry, 31(4), 367-374. DOI: 10.1002/gps.4336

Alzheimer's Research UK (2017). Statistics about dementia. https://www.dementiastatistics.org/statistics-about-dementia/ 
All-Party Parliamentary Group (APPG) on Dementia (July 2013). Dementia does not discriminate. House of Commons. Retrieved https://www.alzheimers.org.uk/downloads/download/1186/appg_2013 bame_report

American Alzheimer's Association (2011) Alzheimer's Association Report. 2011 Alzeimer's descease facts and figures. Alzheimer's and Dementia,7, 208-244.

Askham, J., Briggs, K., Norman, I., \& Redfern, S. (2007). Care at home for people with dementia: As in a total institution?. Ageing and Society, 27(01), 3-24. https://doi.org/10.1017/S0144686X06005307

Aud, M. A. (2004). Dangerous wandering: elopements of older adults with dementia from longterm care facilities. American Journal of Alzheimer's Disease and Other Dementias, 19(6), 361-368. https://doi.org/10.1177/153331750401900602

Bantry White, E., \& Montgomery, P. (2014). Electronic tracking for people with dementia: an exploratory study of the ethical issues experienced by carers in making decisions about usage. Dementia, 13(2), 216-232. https://doi.org/10.1177/1471301212460445

Bantry White, E., \& Montgomery, P. (2015). Dementia, walking outdoors and getting lost: incidence, risk factors and consequences from dementia-related police missing-person reports. Aging \& Mental Health, 19(3), 224-230. https://doi.org/10.1080/13607863.2014.924091

Bosick, S. J., Rennison, C. M., Gover, A. R., \& Dodge, M. (2012). Reporting violence to the police: Predictors through the life course. Journal of Criminal Justice, 40(6), 441-451. https://doi.org/10.1016/j.jcrimjus.2012.05.001 
Clarke, C. L., Keady, J., Wilkinson, H., \& Gibb, C. E. (2011). Risk assessment and management for living well with dementia. Jessica Kingsley Publishers.

Cohn, A. M., Zinzow, H. M., Resnick, H. S., \& Kilpatrick, D. G. (2013). Correlates of reasons for not reporting rape to police results from a national telephone household probability sample of women with forcible or drug-or-alcohol facilitated/incapacitated rape. Journal of Interpersonal Violence, 28(3), 455-473. https://doi.org/10.1177/0886260512455515

College of Policing (2016). Major investigations and public protection. Missing persons.

Retrieved from: https://www.app.college.police.uk/app-content/major-investigation-andpublic-protection/missing-persons/

Connell, C. M., Janevic, M. R., \& Gallant, M. P. (2001). The costs of caring: impact of dementia on family caregivers. Journal of Geriatric Psychiatry and Neurology, 14(4), 179187.

Department of Health (2015). Prime Minister's challenge on dementia 2020. Retrieved from: https://www.gov.uk/government/publications/prime-ministers-challenge-on-dementia-2020

Draper, B. (2013). Understanding Alzheimer's disease and other dementias. London: Jessica Kingsley Publishers.

Eales, N. (2016) iFIND. Sunningdale: National Crime Agency. Retrieved from: http://missingpersons.police.uk/cy-gb/resources/downloads/iFIND

Edkins, J. (2011). Missing: Persons and politics. Cornell University Press. 
Felson, R. B., Messner, S. F., Hoskin, A. H., \& Deane, G. (2002). Reasons for reporting and not reporting domestic violence to the police. Criminology, 40, 617-647. DOI: $10.1111 / \mathrm{j} .1745$ 9125.2002.tb00968.x

Furumiya, J., \& Hashimoto, Y. (2015). A descriptive study of elderly patients with dementia who died wandering outdoors in Kochi Prefecture, Japan. American Journal of Alzheimer's Disease and Other Dementias, 30(3), 307-312. https://doi.org/10.1177/1533317514545826

Gonyea, J. G., Paris, R., \& de Saxe Zerden, L. (2008). Adult daughters and aging mothers: The role of guilt in the experience of caregiver burden. Aging and Mental Health, 12(5), 559-567.

Goudriaan, H., Lynch, J. P., \& Nieuwbeerta, P. (2004). Reporting to the police in western nations: A theoretical analysis of the effects of social context. Justice Quarterly, 21(4), 933969. https://doi.org/10.1080/07418820400096041

Gottfredson, M. R., \& Gottfredson, D. M. (1987). Decision making in criminal justice: Toward the rational exercise of discretion (Vol. 3). Springer Science \& Business Media.

Hillier, L. M., Harvey, D., Conway, C., Hunt, J., \& Hoffman, R. (2016). Finding Your Way'TM: a collaborative approach to increase awareness of missing person events among persons with dementia. Neurodegenerative Disease Management, 6(2), 107-118.

https://doi.org/10.2217/nmt.15.72 
House of Commons Library (October 2016). Dementia: policy, services and statistics.

Retrieved from: http://researchbriefings.parliament.uk/ResearchBriefing/Summary/SN07007

Kääriäinen, J., \& Sirén, R. (2011). Trust in the police, generalized trust and reporting crime. European Journal of Criminology, 8(1), 65-81. https://doi.org/10.1177/1477370810376562

Livingston, G., Leavey, G., Manela, M., Livingston, D., Rait, G., Sampson, E., ... \& Cooper, C. (2010). Making decisions for people with dementia who lack capacity: qualitative study of family carers in UK. BMJ, 341, c4184. https://doi.org/10.1136/bmj.c4184

Mace, N. L., \& Rabins, P. V. (2017). The 36-Hour Day: A Family Guide to Caring for People Who Have Alzheimer Disease, Other Dementias, and Memory Loss. JHU Press.

Marson, S. M., \& Powell, R. M. (2014). Goffman and the Infantilization of Elderly Persons: A Theory in Development. Journal of Sociology \& Social Welfare, 41, 143-158.

Mayor's Office for Policing and Crime (2018) The Herbert Protocol. Safe and found. Metropolitan Police. Retrieved from: https://www.met.police.uk/herbertprotocol

McShane, R., Gedling, K., Keene, J., Fairburn, C., Jacoby, R. \& Hope, T. (1998). Getting lost in dementia. A longitudinal study of a behavioural symptom. International Psychogeriatrics, 10, 253-260. https://doi.org/10.1017/S1041610298005365

Murphy, K., \& Barkworth, J. (2014). Victim willingness to report crime to police: Does procedural justice or outcome matter most? Victims \& Offenders, 9(2), 178-204. https://doi.org/10.1080/15564886.2013.872744 
National Policing Improvement Agency (NPIA) (2011). Alzheimer's safe return project. London: College of Policing.

National Crime Agency (2017). Missing persons data report 2015/2016. UK Missing Persons Buearu. Retrieved from: http://missingpersons.police.uk/en-gb/resources/downloads/missingpersons-statistical-bulletins

Parr, H., \& Fyfe, N. (2013). Missing geographies. Progress in Human Geography, 37(5), 615638. https://doi.org/10.1177/0309132512465919

Prior, P. (2013). Support and care for people with dementia from minority communities. North East Dementia Alliance.

Robinson, L., Hutchings, D., Corner, L., Finch, T., Hughes, J., Brittain, K., \& Bond, J. (2007). Balancing rights and risks: Conflicting perspectives in the management of wandering in dementia. Health, Risk \& Society, 9(4), 389-406.https://doi.org/10.1080/13698570701612774

Rosa, E., Lussignoli, G., Sabbatini, F., Chiappa, A., Di Cesare, S., Lamanna, L., \& Zanetti, O. (2010). Needs of caregivers of the patients with dementia. Archives of Gerontology and Geriatrics, 51(1), 54-58.

Rowe, M. A., \& Bennett, V. (2003). A look at deaths occurring in persons with dementia lost in the community. American Journal of Alzheimer's Disease and Other Dementias, 18(6), 343348. https://doi.org/10.1177/153331750301800612 
Rowe, M. A., \& Glover, J. C. (2001). Antecedents, descriptions and consequences of wandering in cognitively-impaired adults and the Safe Return (SR) program. American Journal of Alzheimer's Disease \& Other Dementias ${ }^{\circledR}, 16(6), 344-352$.

https://doi.org/10.1177/153331750101600610

Rowe, M. A., Feinglass, N. G., \& Wiss, M. E. (2004, November). Persons with dementia who become lost in the community: A case study, current research, and recommendations. In Mayo Clinic Proceedings (Vol. 79, No. 11, pp. 1417-1422). Elsevier.

Rowe, M. A., Vandeveer, S. S., Greenblum, C. A., List, C. N., Fernandez, R. M., Mixson, N. E., \& Ahn, H. C. (2011). Persons with dementia missing in the community: Is it wandering or something unique?. BMC Geriatrics, 11(1), 28. https://doi.org/10.1186/1471-2318-11-28

Rowe, M., Houston, A., Molinari, V., Bulat, T., Bowen, M. E., Spring, H., Mutolo, S., \& McKenzie, B. (2015, November). The Concept of Missing Incidents in Persons with Dementia. In Healthcare (Vol. 3, No. 4, pp. 1121-1132). Multidisciplinary Digital Publishing Institute. DOI: $\underline{10.3390 / \text { healthcare } 3041121}$

Sadler, G. R., Lee, H. C., Lim, R. S. H., \& Fullerton, J. (2010). Recruitment of hard-to-reach population subgroups via adaptations of the snowball sampling strategy. Nursing \& health sciences, 12(3), 369-374. https://doi.org/10.1111/j.1442-2018.2010.00541.x 
Safeguarding Hub (2017) Dementia - An insight into Walking, Wandering and Missing.

Retrieved from; https://safeguardinghub.co.uk/dementia-insight-walking-wandering-missing/

Salari, S. M. (2006). Infantilization as elder mistreatment: evidence from five adult day centers. Journal of Elder Abuse \& Neglect, 17(4), 53-91. https://doi.org/10.1300/J084v17n04_04

Sanders, S., Ott, C. H., Kelber, S. T., \& Noonan, P. (2008). The experience of high levels of grief in caregivers of persons with Alzheimer's disease and related dementia. Death Studies, $32(6), 495-523$

Tarling, R., \& Morris, K. (2010). Reporting crime to the police. The British Journal of Criminology, 50(3), 474-490. https://doi.org/10.1093/bjc/azq011

Tolsma, J., Blaauw, J., \& Te Grotenhuis, M. (2012). When do people report crime to the police? Results from a factorial survey design in the Netherlands, 2010. Journal of Experimental Criminology, 8(2), 117-134. https://doi.org/10.1007/s11292-011-9138-4

UK Missing Persons Bureau (2013). Has someone you know gone missing? Information for carers of people with dementia. Factsheet no. 14. Retrieved from: http://missingpersons.police.uk/en-gb/resources/factsheets-for-families

Vaismoradi, M., Turunen, H., \& Bondas, T. (2013). Content analysis and thematic analysis: Implications for conducting a qualitative descriptive study. Nursing \& Health Sciences, 15(3), 398-405. DOI: $10.1111 /$ nhs. 12048 
Zwaanswijk, M., Peeters, J. M., Van Beek, A. P., Meerveld, J. H., \& Francke, A. L. (2013).

Informal caregivers of people with dementia: problems, needs and support in the initial stage and in subsequent stages of dementia: A questionnaire survey. The Open Nursing Journal, 7 , 6-13. DOI: $\underline{10.2174 / 1874434601307010006}$

\section{Tables}

Table 1: Demographic characteristics of the participants

\begin{tabular}{llll}
\hline & Participant's pseudo name & Gender & Relation to person with dementia \\
\hline 1 & Mark & Male & Husband caring for wife \\
2 & Elliot & Male & Husband caring for wife \\
3 & Paul & Male & Husband caring for wife \\
4 & Kate & Female & Daughter-in-law caring for mother-in-law \\
5 & Carol & Female & Wife caring for husband \\
6 & Brenda & Female & Wife caring for husband \\
7 & James & Male & Husband caring for wife \\
8 & Claire & Female & Daughter caring for mother \\
9 & Julie & Female & Daughter caring for mother \\
10 & Alison & Female & Daughter caring for mother \\
11 & Jane & Female & Daughter caring for mother \\
12 & Stuart & Male & Husband caring for wife \\
\hline
\end{tabular}

Table 2: Missing person incidents

\begin{tabular}{|c|c|c|c|}
\hline & $\begin{array}{l}\text { Participant's } \\
\text { name }\end{array}$ & $\begin{array}{l}\text { Incidents of } \\
\text { becoming } \\
\text { missing }(N)\end{array}$ & $\begin{array}{l}\text { Missing incidents } \\
\text { reported to } \\
\text { the police? }(N)\end{array}$ \\
\hline 2 & Mark & 8 & 2 \\
\hline 3 & Elliot & 1 & 1 \\
\hline 4 & Paul & 25 & 1 \\
\hline 5 & Kate & 2 & 1 \\
\hline 7 & Carol & 1 & 0 \\
\hline 8 & Brenda & 2 & 0 \\
\hline 9 & James & 3 & 1 \\
\hline 11 & Claire & 1 & 0 \\
\hline 12 & Julie & 3 & 3 \\
\hline 13 & Alison & 2 & 0 \\
\hline 14 & Jane & 2 & 0 \\
\hline 15 & Stuart & 2 & 1 \\
\hline
\end{tabular}

